\title{
The vagina of women infected with Trichomonas vaginalis has numerous proteinases and antibody to trichomonad proteinases
}

\author{
J F Alderete, E Newton, C Dennis, K A Neale
}

\begin{abstract}
Background-Patients with trichomoniasis have serum antibody to numerous $T$. vaginalis cysteine proteinases, indicating that the proteinases are expressed in vivo. It was important, therefore, to examine for the presence of soluble trichomonad proteinases and/or antibody to the proteinases in the vagina of infected women.
\end{abstract}

Methods-Vaginal washes (VWs) from 20 women were examined for the presence of proteinases by electrophoresis using acrylamide copolymerised with gelatin as the indicator system. Antibody to proteinases in VWs was detected by an immunoprecipitation assay involving protein A-bearing Staphylococcus aureus first coated with antihuman immunoglobulin G (IgG) antibody, which was then added to VWs. For VWs having soluble proteinases, the bacteria were used to determine whether immune complexes between antibody and proteinases were present. VWs without soluble proteinases were incubated with the anti-human IgG treated bacteria before adding to detergent extracts of $T$. vaginalis. Individual isolates from the patients examined in this study were also analysed by one- and two-dimensional electrophoresis for their proteinase content. Finally, VWs were from patients without any history of other sexually transmitted diseases (STDs) as well as from individuals having numerous other STDs, including yeast, group B streptococcus, chlamydia, and syphilis.

Results-Approximately one-third of patients had soluble proteinases in the VWs; the remaining two-thirds $(70 \%)$ of patients and

Departments of Obstetrics and Gynecology, and Microbiology, The University of Texas Health Science Center, San Antonio, Texas 78284-7758

$\mathrm{J} F$ Alderete

E Newton

C Dennis

K A Neale normal women had no detectable proteinases in VWs. Half of the patients without soluble proteinases had IgG which, when bound to $S$. aureus, immunoprecipitated many proteinases from a detergent extract of $T$. vaginalis. All soluble proteinases and those precipitated from trichomonal extracts were inhibited by inhibitors of cysteine proteinases. Finally, patients having trichomoniasis in addition to numerous other STD agents, including yeast, group B streptococcus, chlamydia, and syphilis did not have soluble proteinases in VWs. Equally noteworthy, some patients with soluble proteinases in VWs did not have other detectable STD agents.

Conclusions-Proteinases were detected in the vagina of some patients with trichomoniasis, and in most cases the proteinases were complexed with IgG, which was precipitated by $\boldsymbol{S}$. aureus. Patients without soluble proteinases in VWs also had antibody specifically to trichomonad proteinases, again demonstrating both the expression and immunogenic nature of the proteinases in vivo. The absence of soluble proteinases in normal women and in patients having other STD agents as well as the presence of proteinases in VWs of patients without other detectable STD pathogens reinforced the idea that the proteinases were of $T$. vaginalis parasite origin. The findings of this study indicate that proteinases may be important to the $T$. vaginalis-host interrelationship.

\section{Introduction}

Trichomonas vaginalis is a sexually transmitted protozoan parasite, which causes for the most part a non-self-limiting disease that affects mostly women. No information on host immunity toward this agent exists, even though antibodies in the vagina of patients, which are reactive with trichomonad immunogens, have been detected. ${ }^{1-3}$ More recently, the specific immunoreactivity of a surface protein by antibody in the vagina of most patients has been demonstrated. ${ }^{4}$

The cysteine proteinases of $T$. vaginalis are known 
to participate in a variety of important virulence properties, such as cytoadherence ${ }^{5}$ and nutrient acquisition, ${ }^{67}$ indicating the possibility for multiple roles of the proteinases during infections. The $T$. vaginalis cysteine proteinases are numerous, ${ }^{89}$ as evidenced by the total number and differential expression of proteinases during in vivo and in vitro growth of isolates. ${ }^{9}$ The presence of the trichomonad proteinases during in vivo infection, many of which are likely to be shed or released during growth, ${ }^{10}$ was recently indicated by the demonstration of serum antibodies to proteinases of this parasite among patients with trichomoniasis. ${ }^{11}$

Few studies have documented a possible role for proteinases in virulence and disease in the vaginal tract. ${ }^{1213}$ Because of this paucity of information and the potential for proteinases of $T$. vaginalis to mediate host cytopathogenicity, ${ }^{14-17}$ we examined for the presence of proteinases in the vagina of patients infected with $T$. vaginalis. This information might provide insight into mechanisms of cytopathogenicity as well as help our understanding of any sequelae in some women. Therefore, vaginal washes (VWs) were evaluated for soluble proteinases and for antibodies to specific trichomonad proteinases.

This report shows the complex patterns of soluble cysteine proteinases in the vagina of some $T$. vaginalis-infected women. Antibody was also found in the vagina of some patients with or without soluble proteinases in VWs, and antibody reacted with the cysteine proteinases present in a $T$. vaginalis detergent extract. The proteinases and vaginal antibody to the trichomonad proteinases in the vaginal washes (VWs) disappeared within one week after treatment and cure of the patients. Our results show the presence of cysteine proteinases, some or all of trichomonal origin, in the vagina of $T$. vaginalisinfected women.

\section{Materials and methods Parasites}

The $T$. vaginalis laboratory isolate NYH $286^{459}$ was used for all experiments because the total proteinase patterns have been previously described. ${ }^{9}$ Trichomonads were passaged daily in trypticase-yeast extract-maltose (TYM) growth medium supplemented with heat-inactivated horse serum. ${ }^{18}$

\section{Protein analysis}

Standard one-dimensional electrophoresis using $\mathbf{7 . 5 \%}$ acrylamide copolymerised with gelatin as substrate, as performed recently, ${ }^{9}$ was used for detection of proteinases. VWs examined for the presence of soluble proteinases were obtained as described below. Isolates of $T$. vaginalis from some patients were axenized and grown for several days in the TYM-serum medium before also analyzing for proteinases.

\section{$V W$ antibody}

Patients attending the Brady Green Outpatient clinic in San Antonio were diagnosed as being infected with $T$. vaginalis by microscopic examination and positive cultures. These same patients and normal women controls were also examined for the presence of other sexually transmitted disease (STD) agents. The patients diagnosed with trichomoniasis and other STD pathogens and their clinical presentations at the time of examination are represented in the table. VWs were obtained from these individuals prior to treatment with metronidazole and re-examination one week later.

VWs $(2 \mathrm{ml}$ to $3 \mathrm{ml}$ ) were obtained as has been described before ${ }^{1920}$ and processed by a previously published procedure on the removal of vaginal epithelial cells (VECs) from the $\mathrm{VW}^{20}$ before analysing for soluble proteinases. ${ }^{9}$ Briefly, VWs were first subjected to low speed centrifugation $(500 \times g)$ to remove VECs from the VW also containing antibody and bacteria. The pelleted VECs were then further purified by fractionation through nylon mesh screens to separate them from trichomonads. ${ }^{20} \mathrm{VWs}$ were also obtained from volunteers without a history of sexually transmitted diseases and processed identically for use as negative controls. After removing the VECs, the supernatants were centrifuged at $17,500 \times g$ to pellet contaminating bacteria followed by filtering through a $0.2 \mu \mathrm{m}$ acrodisk filter (Gelman Sciences, Ann Arbor, MI). An aliquot of this supernatant was then mixed with an equal volume of electrophoresis dissolving buffer ${ }^{21}$ and electrophoresed for detection of proteinases. ${ }^{9}$

\section{Immunoprecipitation assays}

Immunoprecipitation was performed using an extract of $2 \times 10^{6}$ trichomonads solubilised in $200 \mu \mathrm{l}$ of $0.05 \%$ Zwittergent 3-12 (Z3-12) (CalbiochemBehring Co., La Jolla, CA) prepared in PBS. ${ }^{49}$ One hundred microliters of $10 \%(\mathrm{w} / \mathrm{v})$ fixed $S$. aureus in PBS- $0.05 \%$ Z3-12 was incubated with an equal volume of 1:200 dilution of goat anti-human IgG serum (BioRad Laboratories, Richmond, CA) for two hours at $4^{\circ} \mathrm{C}^{4}$ After washing twice, pretreated $S$. aureus was resuspended in $100 \mu \mathrm{l}$ of PBS $-0.05 \% \mathrm{Z3}$ 12 and then incubated with a $1 \mathrm{ml}$ volume of $\mathrm{VW}$ processed as above. To determine specific anti-trichomonad proteinase antibody, only VW devoid of soluble proteinases was used. The $S$. aureus with bound VW antibody was used to immunoprecipitate proteinases from a Z3-12 detergent extract of $T$. vaginalis NYH 286 as previously described. ${ }^{4}$ The bacteria were washed twice in PBS- $0.05 \% \mathrm{Z3}-12$ followed by suspending bacteria in dissolving buffer ${ }^{21}$ and releasing proteinases complexed with antibody by heating at $37^{\circ} \mathrm{C}$ for three minutes. The bacteria were pelleted and supernatant electrophoresed for detection of proteinases. 
Table Summary of characteristics and other variables in the vagina of twelve patients with trichomoniasis

\begin{tabular}{|c|c|c|c|c|c|c|c|c|c|c|c|c|}
\hline \multirow[b]{4}{*}{ Characteristics } & \multicolumn{12}{|c|}{ Sample number: } \\
\hline & 1 & $4^{\star}$ & 5 & $6 \star$ & $7 \star$ & 10 & 12 & 3 & 8 & 9 & 11 & 13 \\
\hline & \multicolumn{12}{|c|}{ Presence of soluble proteinases in $V W:$} \\
\hline & - & & & & & & & + & & & & \\
\hline $\begin{array}{l}\text { vaginal pH } \\
\text { discharge } \dagger \\
\text { discomfort } \dagger \\
\text { inflammation } \dagger \\
\text { virulence properties } \star \star \\
\text { VW Ab to proteinases } \dagger \dagger \\
\text { VW Ab to Immunogen } \ddagger\end{array}$ & $\begin{array}{l}5 \cdot 0 \\
+ \\
+ \\
+ \\
+ \\
-\end{array}$ & $\begin{array}{l}7 \cdot 0 \\
+ \\
+ \\
+ \\
+ \\
-\end{array}$ & $\begin{array}{l}5 \cdot 0 \\
+ \\
- \\
+ \\
+ \\
+ \\
+\end{array}$ & $\begin{array}{l}5 \cdot 0 \\
+ \\
+ \\
+ \\
+ \\
+\end{array}$ & $\begin{array}{l}7 \cdot 0 \\
+ \\
+ \\
+ \\
+ \\
+ \\
+\end{array}$ & $\begin{array}{l}5 \cdot 7 \\
+ \\
+ \\
+ \\
+ \\
+\end{array}$ & $\begin{array}{l}4 \cdot 49 \\
- \\
- \\
+ \\
+ \\
+\end{array}$ & $\begin{array}{l}7 \cdot 0 \\
+ \\
- \\
- \\
+ \\
+ \\
+\end{array}$ & $\begin{array}{l}7 \cdot 0 \\
+ \\
+ \\
+ \\
+ \\
+ \\
+\end{array}$ & $\begin{array}{l}5 \cdot 0 \\
+ \\
+ \\
+ \\
+ \\
+ \\
+\end{array}$ & $\begin{array}{l}7 \cdot 0 \\
+ \\
+ \\
+ \\
+ \\
+ \\
+\end{array}$ & $\begin{array}{l}\text { NA } \\
\text { NA } \\
\text { NA } \\
\text { NA } \\
+ \\
+ \\
+\end{array}$ \\
\hline $\begin{array}{l}\text { Other pathogens§ } \\
\text { Bacterial vaginosis score§ }\end{array}$ & none & none & Yeast & $\begin{array}{l}\text { UTI } \\
\text { Yeast } \\
8\end{array}$ & $\begin{array}{l}\text { UTI } \\
\text { Yeast } \\
4\end{array}$ & $\begin{array}{l}\text { Yeast } \\
\text { syphilis } \\
\text { GBS } \\
10\end{array}$ & $\begin{array}{l}\text { Yeast } \\
0\end{array}$ & $\begin{array}{l}\text { GBS } \\
\text { NA }\end{array}$ & $\begin{array}{l}\text { UTI } \\
\text { Yeast } \\
\text { chlam. } \\
5\end{array}$ & $\begin{array}{l}\text { UTI } \\
\text { chlam. } \\
8\end{array}$ & $\begin{array}{l}\text { none } \\
7\end{array}$ & $\begin{array}{l}\text { none } \\
6\end{array}$ \\
\hline
\end{tabular}

^Isolates of sample number 4, 6, and 7 have been designated T005, T010, and T012, respectively, and have been examined before ${ }^{9}$ for proteinase activities. Two-dimensional electrophoresis with gelatin copolymerised with acrylamide have been performed on these and numerous other fresh isolates, as reported previously, ${ }^{9}$ and all isolates, regardless of the presence or absence of proteinases in VWs, possessed numerous proteinase activities.

$\llbracket T$. vaginalis organisms were readily detected and isolated from a patient with this vaginal $\mathrm{pH}$. The ability of some isolate trichomonads to survive this $\mathrm{pH}$ was recently demonstrated. ${ }^{27}$

† Symptomatology was assessed on the basis of three parameters. Most patients, as indicated, had a discharge described as creamy white and mucoid. Discomfort was defined on the basis of odor, itching, bleeding, pain during intercourse and/or some other overt sign. Inflammation was either erythemia or ectropion.

$\star \star$ The previously established properties of cytoadherence, contact-dependent cytotoxicity, and haemagglutination-haemolysis were used as a measure of virulence capability for all isolates.

††The presence of antibody (Ab) in VWs was examined. VW Ab was directed toward the soluble cysteine proteinases present in VWs (samples $3,8,9,13$, and 11) (figure 1) or was toward trichomonad proteinases as described in the Results (fig 2) in the case of VWs without soluble proteinases.

†The presence of VWs in antibody toward a surface protein immunogen with a $M_{r}$ of 230,000 was determined as recently reported. ${ }^{4}$

§̧outine examination was performed on all patients for candidiasis (yeast), urinary tract infections (UTI), syphilis, group B streptococcal infection (GBS), and chlamydia (chlam.). It is noteworthy that some patients with trichomoniasis and having soluble proteinases in VWs (samples 11 and 13) had no other detectable pathogens. Also, numerous VWs that had no soluble proteinases (samples 5, 6, 7, 10, and 12, for example) were from trichomoniasis patients that had concomitant infections with other pathogens.

Bacterial vaginosis was performed and assigned a relative score as described in ref 28 .

NA, not available.

Clarified VWs were also treated directly with washed $S$. aureus to detect any existing immune complexes between vaginal antibody and soluble proteinases. In this case, Z3-12 detergent $(0.05 \%$ final concentration) was added to and mixed with the VWs. After centrifugation at $10,000 \times g$ to remove any insoluble debris, $100 \mu \mathrm{l}$ of $S$. aureus washed as above was added to $1 \mathrm{ml}$ of the VW and incubated as before.

\section{Results}

Cysteine proteinases are in VWs of some women with $T$. vaginalis infections

The supernatants of VWs clarified of vaginal epithelial cells and bacteria were tested for the presence of soluble proteinases. Analysis of several VWs revealed distinct but reproducible patterns of multiple proteinases as shown in fig 1 (part B). Although six of twenty positive VWs contained proteinases with $\mathrm{M}_{\mathrm{r}}$ between $\sim 65-\mathrm{kDa}$ to $>200-\mathrm{kDa}$, two washes had strong proteinase activities below $65-\mathrm{kDa}$, as seen for patient sample number 8 . It is noteworthy that duplicate washes first incubated for 20 minutes with $1 \mathrm{mM}$ TLCK, an inhibitor of cysteine proteinases, totally abolished the proteinase activities. The possibility that the procedure for clarifying VW from VECs resulted in lysis of $T$. vaginalis organisms, known to contain many proteinases like those seen for sample $8,{ }^{9}$ was discounted for two reasons. Live parasites were also present in the starting VWs of many patients that did not have soluble proteinases. Also, mock experiments with VWs of normal women were contaminated with in vitro-grown trichomonads. These VWs had no detectable soluble proteinases after processing identically. The data also suggest that the proteinases were neither of host origin nor of contaminating STD pathogens. For example, the table shows that many VWs from patients who had other STD pathogens had no detectable proteinases (samples 5, 6, 7, 10, and 12). Equally important, VWs with soluble proteinases were from patients without any other pathogens (table, samples 11 and 13). Under no circumstances were soluble proteinases seen in women without $T$. vaginalis and with or without other STD pathogens. Finally, trichomonal 


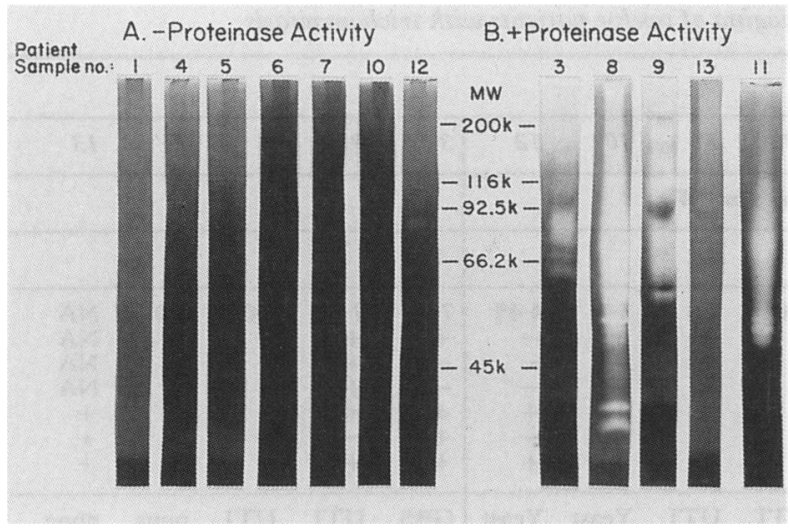

Fig 1 Representative patterns showing the absence $(A)$ and presence $(B)$ of soluble proteinase activities present in clarified $V W$ of patients with trichomoniasis. The different proteinase patterns of individual $V W s$ were identical in each of triplicate experiments conducted at separate times, showing the reproducibility of the experiments.

isolates of some patients were examined for proteinase activity. Not surprisingly and consistent with earlier published results, ${ }^{89}$ analysis revealed complex patterns indicative of numerous proteinases for all isolates.

Does VW have antibody to trichomonad proteinases? We wanted to test whether the VWs had any antibody specific for the proteinases of $T$. vaginalis, especially since a recent study by us demonstrated the reactivity of vaginal antibody toward a high $M_{r}$ immunogen. ${ }^{4}$ Addition of $S$. aureus alone to VWs, which had soluble proteinases, surprisingly precipitated proteinases, as shown for a representative reaction in fig 2 (patient sample no. 3 ). No proteinases were precipitated by $S$. aureus bacteria added to a trichomonal lysate, suggesting that the bacteria were reacting with existing antibodyproteinase immune complexes in VWs.

Because of this finding we were able to test only VWs without soluble proteinases for specific antitrichomonad proteinase antibody. $S$. aureus pretreated with anti-human Ig were incubated with VWs lacking soluble proteinases (fig 2, all samples except no. 3) followed by addition of bacteria to a trichomonal detergent extract. ${ }^{9}$ Half (7) of the VWs without soluble proteinases possessed antibody to trichomonad proteinases, as evidenced by the complex proteinase patterns seen in patient samples 2,5 , and 7 . The $S$. aureus with anti-human Ig antibodies failed to precipitate any proteinases from the detergent extract in duplicate samples in the same experiment, an evidence for the specificity of the reaction. ${ }^{9}$ Finally, the variations in patterns of proteinase activity based on antibody precipitation of the proteinases may not be unexpected considering a recent report on the differential expression of proteinases by $T$. vaginalis isolates. ${ }^{9}$

\section{Proteinases and antibody to proteinases disappear following treatment}

Figure 3 illustrates the proteinase activity from VWs of two patients before (lane 1) and after (lane 2) treatment with metronidazole. The VWs were obtained at the time of diagnosis and 7 days after treatment, at which time the patient tested negative for $T$. vaginalis by wet mount and culture assays. VWs from patients without soluble proteinase activity but with antibody (fig 2 , samples 5 and 7 ), also gave no evidence of antibody after treatment, further reaffirming the short-lived nature of both the proteinases and the anti-proteinase antibody response.

\section{Discussion}

This study reaffirms both the highly immunogenic nature and the presence during trichomoniasis of Trichomonas vaginalis cysteine proteinases. ${ }^{911}$ It is noteworthy that many patients had soluble proteinases in VWs (fig 1), and the precipitation of the soluble proteinases by $S$. aureus indicated the pos-

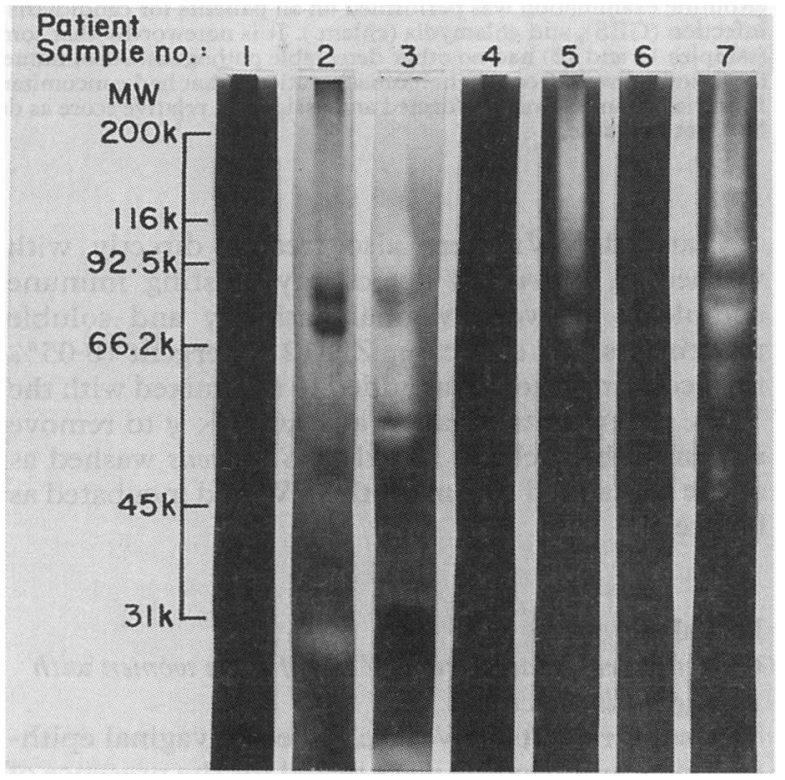

Fig 2 Detection of antibody reactive with proteinases in $V W$ s of patients with trichomoniasis. For these samples the clarified washes were incubated with $S$. aureus containing bound goat anti-human Ig antibody. The immunoprecipitation experiment was as described in Materials and Methods, based on an earlier publication. ${ }^{9}$ It is noteworthy that some samples, like those of numbers 2,5 , and 7, did not possess soluble proteinases in their vaginal wash (fig 1) but did have antibody. 


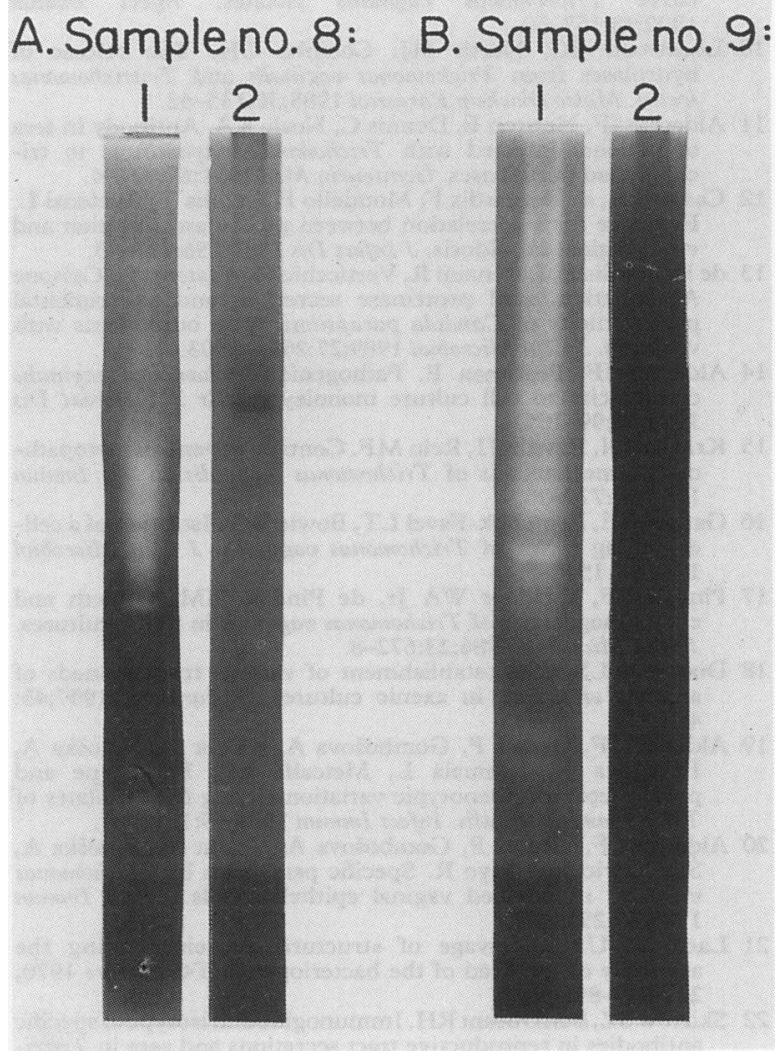

Fig 3 Demonstration of the disappearance of proteinase activity and antibody in VWs after treatment of two trichomoniasis patients. Lane 1 for samples 8 and 9 are of proteinase activity in $V W$ and gave similar proteinase patterns as those seen in an earlier experiment (fig 1). Lane 2 shows the absence of proteinases in VW obtained one week after treatment. These samples also had antibody complexed to proteinases in their vaginal washes before treatment, which disappeared after treatment as seen for lane 2 (data not shown). Antibody was measured by the immunoprecipitation assay as described in Materials and Methods.

sibility that the proteinases were already complexed with antibody. Also, that VWs without detectable soluble proteinases (fig 1A) had antibody to the $T$. vaginalis proteinases was demonstrated by the fact that the source of the precipitated proteinases was a detergent extract of the parasite. This finding was in agreement with the recent observation that sera of patients with trichomoniasis had antibody to the cysteine proteinases of $T$. vaginalis. ${ }^{11}$ That the antibody already complexed with proteinases in some patients (fig 2) was indeed anti-trichomonal antibody and that the soluble proteinases were of $T$. vaginalis origin, however, could not be proven experimentally. Also, isolates from patients, regardless of whether VWs had soluble proteinases or not, had complex proteinase patterns (table). ${ }^{9}$ These findings were not unexpected, based on earlier work, ${ }^{8911}$ and the differences in the proteinases activities seen in the immunoprecipitation results (fig 2B) may simply be a reflection of antibody responses to a subset of proteinases differentially expressed and predominating during infection. ${ }^{9}$ The divergent patterns seen for the proteinases of the VWs, assuming they were of trichomonal origin, might also be explained similarly. ${ }^{9}$

Another possibility to account for the diverse patterns of the cysteine proteinases in the vagina of patients might be the contamination of the vagina by other STD pathogens (table). This alternative does not appear plausible for several reasons. Patients, as presented in the table, also had other STD pathogens yet gave no detectable proteinases (samples 5-7, 10 and 12). Likewise, patients without other infectious agents still gave strong, complex proteinase patterns (samples 11 and 13). Finally, women without trichomoniasis and with or without other STD pathogens such as those presented in the Table never gave any detectable proteinase activity. Although these data are not direct proof, it seems highly likely that the soluble proteinases were of trichomonal origin.

Although antibody in VWs and secretions has been documented for pathogenic trichomonads, including $T$. vaginalis ${ }^{1-4}$ and Tritrichomonas foetus, ${ }^{22}$ the exact immunoreactivity with $T$. vaginalis immunogens had, for the most part, remained undefined. In this report the existence of anti-proteinase antibody in vaginal secretions has been established, albeit only for some patients. This anti-proteinase antibody, while possibly a host response to the proteinasemediated host cytopathology, may also inadvertently contribute to the non-self-limiting nature of the infection. For example, the antibody may prevent sufficient injury from occurring to the host that would otherwise elicit a more severe and possibly protective anti-trichomonal immune response for elimination of the parasite. Since drug treatment is needed for cure of infection, this anti-proteinase response may be of little or no value in host protection. It was not possible to obtain information on the rapidity of the vaginal anti-proteinase antibody response, as the patient's length of infection by the parasite prior to seeking medical attention was unknown or difficult to ascertain.

The short-lived nature of the vaginal (fig 3) and serum $^{11}$ antibody to proteinases after drug treatment of patients was noteworthy. This disappearance of soluble cysteine proteinases and anti-proteinase antibody following treatment may represent future molecular markers for confirming eradication of the parasite and a vaginitis and for possibly re-establishment of normal conditions in the vagina. This report reinforces the idea suggested earlier ${ }^{5}$ that, in the event of no future vaccine for protection against this parasite, the development and generation of reagents ${ }^{23}$ that selectively inhibit the proteinases as 
shown here, regardless of their microbial aetiology, be continued. Lastly, as presented in the table, it was difficult to establish any association between symptomatology and the presence or absence of either proteinases or anti-proteinase antibody. In each patient no clear-cut relationship between signs and symptoms and qualitative or quantitative levels or patterns of proteinases or antibody to proteinases could be established. This lack of correlations is consistent with the reports that show the difficulty of attempting to assign direct host immune responses or parasite products with signs and symptoms of trichomoniasis. ${ }^{24-26}$

This study was supported by Public Health Service grants AI-22380 and AI-31498 from the National Institute of Allergy and Infectious Diseases and by a grant from the South Texas Vaccine Development Center. The excellent secretarial assistance of Diana Hinojosa is especially acknowledged.

Address for correspondence: Dr John F Alderete, Department of Microbiology, UTHSCSA, 7703 Floyd Curl Dr., San Antonio, Texas 78284-7758.

1 Alderete JF. Enzyme-linked immunosorbent assay for detection of antibody to Trichomonas vaginalis: Use of whole cells and aqueous extract as antigen. $\mathrm{BrJVenereal} \mathrm{Dis} \mathrm{1984;60:164-70.}$

2 Street DA, Taylor-Robinson DP, Ackers J, Hanna NF, McMillan A. Evaluation of an enzyme-linked immunosorbent assay for the detection of antibody to Trichomonas vaginalis in sera and vaginal secretions. Br J Venereal Dis 1982;58:330-3.

3 Su KW. Antibody to Trichomonas vaginalis in human cervicovaginal secretions. Infect Immun 1982;37:852-7.

4 Alderete JF, Newton E, Dennis C, Engbring J, Neale KA. Vaginal antibody of patients with trichomoniasis is to a prominent surface immunogen of Trichomonas vaginalis. Genitourin Med 1991;67:220-5.

5 Arroyo R, Alderete JF. Trichomonas vaginalis proteinase activity is necessary for parasite cytadherence. Infect Immun 1989; 57:2991-7.

6 Dailey DC, Chang T, Alderete JF. Characterization of a hemolysin of Trichomonas vaginalis. Parasitology 1990;101: 171-75.

7 Lehker MW, Chang TH, Dailey DC, Alderete JF. Specific erythrocyte binding is an additional nutrient acquisition system for Trichomonas vaginalis. J Exp Med 1990;171: 2165-70.

8 Lockwood BC, North MJ, Scott KI, Bremner AF, Coombs GH. The use of a highly sensitive electrophoretic method to compare the proteinases of trichomonads. Mol Biochem Parasitol 1987;24:89-95.

9 Neale KA, Alderete JF. Analysis of the proteinases of represen- tative Trichomonas vaginalis isolates. Infect Immun 1990;58:157-62.

10 Lockwood BC, North MJ, Coombs GH. The release of hydrolases from Trichomonas vaginalis and Tritrichomonas foetus. Molec Biochem Parasitol 1988;30:135-42.

11 Alderete JF, Newton E, Dennis C, Neale KA. Antibody in sera of patients infected with Trichomonas vaginalis is to trichomonad proteinases. Genitourin Med 1991;67:331-4.

12 Cassone A, de Bernardis F, Mondello F, Ceddia T, Agatensi $L$. Evidence for a correlation between proteinase secretion and vulvovaginal candidosis. J Infect Dis 1987;156:777-83.

13 de Barnardis F, Lorenzini R, Verticchio R, Agatensi L, Cassone A. Isolation, acid proteinase secretion, and experimental pathogenicity of Candida parapsilosis from outpatients with vaginitis. J Clin Microbiol 1989;27:2598-2603.

14 Alderete JF, Pearlman E. Pathogenic Trichomonas vaginalis cytotoxicity to cell culture monolayers. $\mathrm{Br} J$ Venereal $D$ is 1984;60:99-105.

15 Krieger JN, Ravdin JI, Rein MF. Contact-dependent cytopathogenic mechanisms of Trichomonas vaginalis. Infect Immun 1985;50:778-86.

16 Garber GE, Lemchuk-Favel LT, Bowie WR. Isolation of a celldetaching factor of Trichomonas vaginalis. J Clin Microbiol 1989;27:1548-55.

17 Pindak FF, Gardner WA Jr, de Pindak MM. Growth and cytopathogenicity of Trichomonas vaginalis in tissue cultures. J Clin Microbial 1986;23:672-8.

18 Diamond LS. The establishment of various trichomonads of animals and man in axenic cultures. $J$ Parasitol 1957;43: 488-90.

19 Alderete JF, Demeš P, Gombošova A, Valent $M$, Janoška $A$, Fabušova H, Kasmala $L$, Metcalfe EC. Phenotype and protein/epitope phenotypic variation among fresh isolates of Trichomonas vaginalis. Infect Immun 1987;55:1037-41.

20 Alderete JF, Demeš $P$, Gombošova $A$, Valent $M$, Janoška $A$, Stefanovic J, Arroyo R. Specific parasitism by Trichomonas vaginalis of purified vaginal epithelial cells. Infect Immun 1988;56:2558-62.

21 Laemmli UK. Cleavage of structural proteins during the assembly of the head of the bacteriophage T4. Nature 1970; 227:680-85.

22 Skirrow SZ, BonDurant RH. Immunoglobulin isotype of specific antibodies in reproductive tract secretions and sera in Tritrichomonas foetus-infected heifers. Am J Veterin Res 1990; 51:645-53.

23 Björck L, Akesson P, Bohus M, Trojnar J, Abrahamson M, Olafsson I, Grubb A. Bacterial growth blocked by a synthetic peptide based on the structure of a human proteinase inhibitor. Nature 1989;337:385-6.

24 Schaaf VM, Perez-Stable EJ, Borchardt $K$. The limited value of symptoms and signs in the diagnosis of vaginal infections. Arch Intern Med 1990;150:1929-33.

25 Wlner-Hanssen P, Krieger JN, Stevens CE, Kiviat NB, et al. Clinical manifestations of vaginal trichomoniasis. JAMA 1989;261:571-6.

26 Fouts AC, Kraus SJ. Trichomonas vaginalis: reevaluation of its clinical presentation and laboratory diagnosis. J Infect Dis 1980;141:137-43.

27 Lehker MW, Alderete JF. Properties of Trichomonas vaginalis grown under chemostat controlled growth conditions. Genitourin Med 1990;66:193-9.

Accepted for publication 2 September 1991 